\title{
ChemComm
}

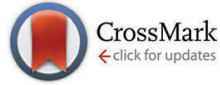

Cite this: Chem. Commun., 2016, 52,7588

Received 1st May 2016, Accepted 13th May 2016

DOI: $10.1039 / \mathrm{c} 6 \mathrm{cc} 03631 \mathrm{~g}$

www.rsc.org/chemcomm

\section{Fluorescence enhancement through the formation of a single-layer two-dimensional supramolecular organic framework and its application in highly selective recognition of picric acid $\dagger$}

\author{
Ying Zhang, Tian-Guang Zhan, Tian-You Zhou, Qiao-Yan Qi, Xiao-Na Xu and \\ Xin Zhao*
}

\begin{abstract}
A two-dimensional (2D) supramolecular organic framework (SOF) has been constructed through the co-assembly of a triphenylaminebased building block and cucurbit[8]uril (CB[8]). Fluorescence turn-on of the non-emissive building block was observed upon the formation of the 2D SOF, which displayed highly selective and sensitive recognition of picric acid over a variety of nitroaromatics.
\end{abstract}

Materials with periodical and well-ordered internal pores, represented by metal organic frameworks $(\mathrm{MOFs})^{1}$ and covalent organic frameworks (COFs) ${ }^{2}$ have drawn considerable attention in the past decades because of their important applications in many aspects ranging from absorption, separation, delivery, catalysis to molecular recognition. ${ }^{3}$ Generally MOFs or COFs are constructed via strong coordination interactions or dynamic covalent bonds. In principle, MOF or COF-like frameworks should also be constructed through weak interactions, which however turn out to be very challenging. One main reason is that weak interactions are usually not strong enough to generate frameworks with size comparable to MOFs or COFs. To address this challenge, the use of noncovalent interactions which exhibit strong bonding strength is required.

Host-guest interactions, which usually occur between a cyclic host molecule and one or more guest molecules, have been widely employed to construct supramolecular architectures. ${ }^{4}$ Among them cucurbit[8]uril (CB[8])-based host-guest chemistry has drawn considerable attention because of the high bonding strength and $1: 2$ binding stoichiometry which provides a facile approach to connect two pieces of building blocks. ${ }^{5}$ In the past two decades, $\mathrm{CB}[8]$ has been demonstrated to be a versatile host to fabricate a variety of supramolecular structures. ${ }^{6}$ Very recently $\mathrm{CB}[8]$-based host-guest interactions have been utilized by us and others to construct a new type of MOF- or COF-like porous material, that is, supramolecular organic frameworks (SOFs). ${ }^{7}$

Key Laboratory of Synthetic and Self-Assembly Chemistry for Organic Functional Molecules, Shanghai Institute of Organic Chemistry, Chinese Academy of Sciences, 345 Lingling Road, Shanghai 200032, China. E-mail: xzhao@mail.sioc.ac.cn $\dagger$ Electronic supplementary information (ESI) available: Synthesis and characterization, Job's plot, DLS plot, NOESY and DOSY spectra, and additional fluorescence spectra. See DOI: 10.1039/c6cc03631g
Recently, research studies in this area have mainly focused on the construction of SOFs with novel structures and development of new fabrication approaches. The applications of SOFs have rarely been demonstrated. Very recently Li and Liu reported that SOFs could be excellent porous materials to absorb guest molecules. ${ }^{8}$ In this communication, we report a remarkable fluorescence emission enhancement through the formation of a $2 \mathrm{D} \mathrm{SOF}$ self-assembled from a triphenylamine-based building block and $\mathrm{CB}[8]$ in the aqueous phase. The as-formed 2D SOF was further used as a fluorescent chemosensor to detect picric acid (PA) with high selectivity and sensitivity (Scheme 1).

We previously developed a series of host-guest systems on the basis of the encapsulation of two 4-aryl- $\mathrm{N}$-methylpyridinium inside the cavity of $\mathrm{CB}[8] .{ }^{9}$ In order to construct an extended network in 2D space, building block 1 was designed by incorporating three 4-( $p$-methoxy-phenyl)-1-pyridinium (MPP) units onto the periphery of a triphenylamine skeleton. In order to improve its solubility in aqueous media, a chloride ion was selected as the counterion of pyridinium. The binding behaviour between $\mathrm{CB}[8]$ and 1 was investigated by the ${ }^{1} \mathrm{H}$ NMR titration experiment. Since 1 has limited solubility in water, a binary solvent $\mathrm{D}_{2} \mathrm{O}-\mathrm{CD}_{3} \mathrm{OD}$ $(17: 3, \mathrm{~V} / \mathrm{V})$ was used for the titration experiment. As shown in Fig. 1, upon the gradual addition of $\mathrm{CB}[8]$ into a solution of $\mathbf{1}$, a new set of peaks arose in the range of 9.0-6.7 ppm, accompanied by a decrease of the intensities of original peaks of 1 . The new set of peaks could be assigned to the encapsulated 1 in the cavity of $\mathrm{CB}[8]$. The signals of unencapsulated 1 completely disappeared when the molar ratio of 1 to $\mathrm{CB}[8]$ reached $2: 3$. Further addition of $\mathrm{CB}[8]$ did not cause observable change in the ${ }^{1} \mathrm{H}$ NMR spectrum, suggesting that the binding stoichiometry between 1 and $\mathrm{CB}[8]$ was $2: 3$. This stoichiometry was further confirmed by a Job's plot, which displayed a maximum absorption change at $40 \%$ of $\mathbf{1}$ in a mixture of $\mathbf{1}$ and $\mathrm{CB}[8]$ in watermethanol $(17: 3, \mathrm{~V} / \mathrm{V})$ (Fig. S1, ESI $\dagger$ ).

It is expected that $2 \mathrm{D}$ polymeric structures should be formed through the host-guest interactions between $\mathbf{1}$ and $\mathrm{CB}[8]$, which is directed by the head-to-tail dimerization of MPP units of the rigid $C_{3}$ symmetric 1 in the cavities of $\mathrm{CB}[8]$ molecules. This binding 


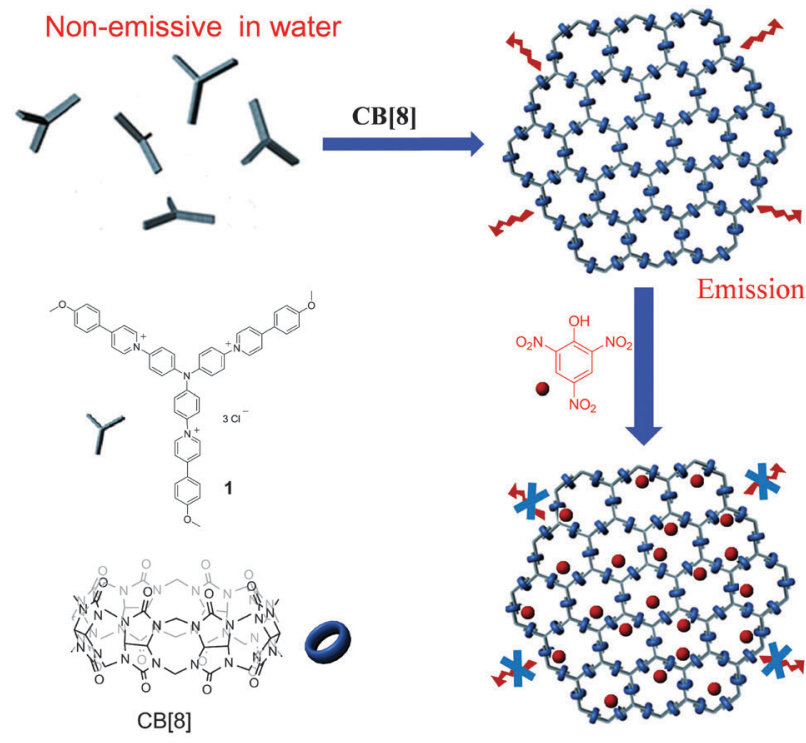

Emission quenched

Scheme 1 The chemical structures of compound 1 and $C B[8]$ and cartoon representation for the formation of the 2D SOF and its application as a highly selective picric acid sensor.

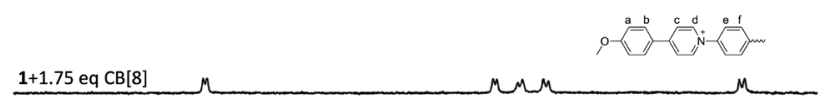

$1+1.5$ eq $\mathrm{CB}[8]$

$1+1.25$ eq $\mathrm{CB}[8]$

$1+1$ eq $\mathrm{CB}[8]$

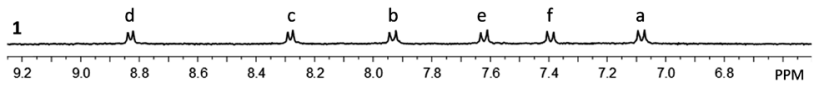

Fig. 1 Partial ${ }^{1} \mathrm{H}$ NMR spectra of 1 and $\mathrm{CB}[8]$ at different molar ratios in $\mathrm{D}_{2} \mathrm{O}-\mathrm{CD}_{3} \mathrm{OD}(17: 3, \mathrm{~V} / \mathrm{V})$ at $25^{\circ} \mathrm{C}$. The concentration of 1 was fixed at $1.0 \mathrm{mM}$.

model has already been demonstrated in the previous studies ${ }^{9}$ and was further confirmed here by the $2 \mathrm{D}{ }^{1} \mathrm{H}$ NMR NOESY spectrum which showed intermolecular NOE connections between $\mathrm{H}_{\mathrm{a}}$ and $\mathrm{H}_{\mathrm{d}}$, and $\mathrm{H}_{\mathrm{b}}$ and $\mathrm{H}_{\mathrm{d}}$ (Fig. S2, ESI $\dagger$ ). The dynamic light scattering (DLS) experiment at different concentrations revealed that the hydrodynamic diameter $\left(D_{\mathrm{h}}\right)$ of the mixture of 1 and $\mathrm{CB}[8](2: 3)$ in water-methanol $(17: 3, \mathrm{~V} / \mathrm{V})$ increased with the increase of the concentration and reached a value of $98 \mathrm{~nm}$ at a concentration of $\mathbf{1}$ of $0.5 \mathrm{mM}$ (Fig. S3, ESI $\dagger$ ), indicating the formation of large aggregates in solution. It was further confirmed by $2 \mathrm{D}^{1} \mathrm{H}$ NMR diffusion ordered spectroscopy (DOSY) study. The DOSY spectra showed that the values of diffusion coefficients (D) decreased from $1.92 \times 10^{-10} \mathrm{~m}^{2} \mathrm{~s}^{-1}$ for the solution of compound 1 to $9.16 \times 10^{-11} \mathrm{~m}^{2} \mathrm{~s}^{-1}$ after the addition of $\mathrm{CB}[8](\mathbf{1} / \mathrm{CB}[8]=2 / 3)$ (Fig. S4 and S5, ESI $\dagger$ ), suggesting aggregates of large size from 1 and $\mathrm{CB}[8]$.

In order to visualize the morphology of the aggregates formed, the as-prepared material was investigated by transmission electron
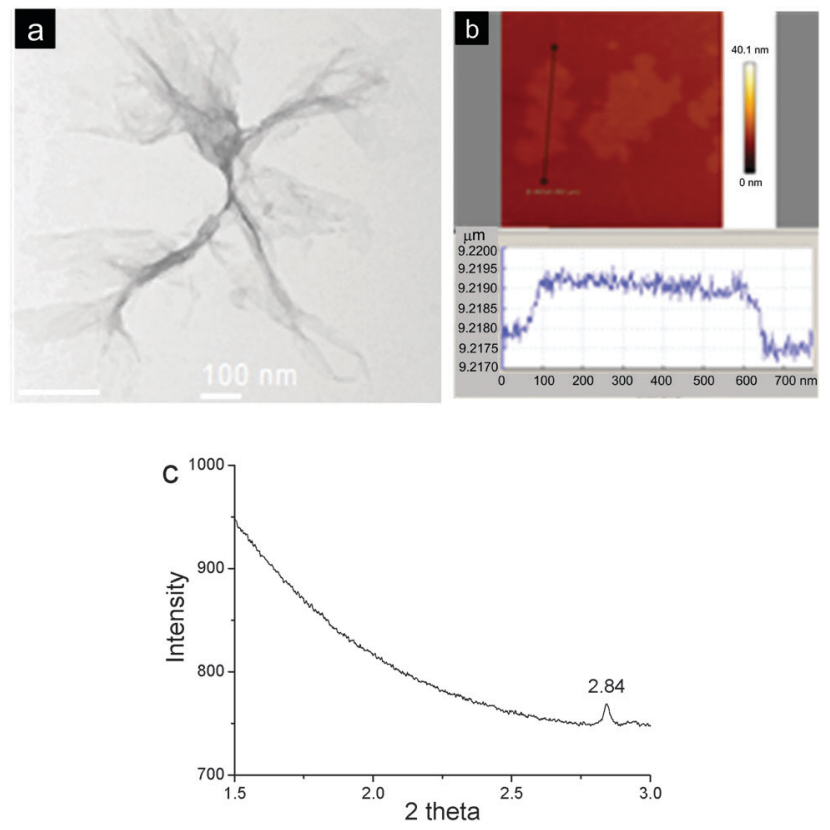

Fig. 2 (a) TEM image of the SOF fabricated from $1(0.0125 \mathrm{mM})$ and $C B[8]$ $(0.0188 \mathrm{mM})$, (b) tapping-mode AFM image and section analysis of the SOF fabricated from $1(0.0125 \mathrm{mM})$ and $\mathrm{CB}[8](0.0188 \mathrm{mM})$, and (c) synchrotron SAXS profiles of the SOF obtained by evaporating its solution. The SOF was prepared by dissolving a mixture of 1 and $\mathrm{CB}[8](2: 3)$ in water-methanol $(17: 3, V / V)$ and standing overnight without disturbance at room temperature.

microscopy (TEM) and atomic force microscopy (AFM). The TEM image revealed that the aggregates possessed film-like structures and part of them were of corrugation. The films exhibited very low contrast to a carbon film-coated TEM grid, suggesting the formation of extremely thin 2D materials (Fig. 2a). It should be noted that the as-formed films were unstable under an electron beam of TEM, which led to damage to part of the films after the image was taken. AFM also indicated the formation of flat and uniform films with the lateral size to be around several hundred nanometers. And the thickness of a typical film was measured to be $c a .2 .0 \mathrm{~nm}$ (Fig. 2b). This value agreed well with the diameter of rigid $\mathrm{CB}[8]$ $(1.75 \mathrm{~nm}),{ }^{6 b}$ confirming the formation of a single-layer 2D SOF. The as-prepared materials were also investigated by a synchrotron small angle X-ray scattering (SAXS) technique. A sharp peak at a $2 \theta$ value of 2.84 was observed (Fig. 2c), which corresponds to a periodic distance of $3.52 \mathrm{~nm}$. This value is well consentient with the theoretical pore diameter $(3.60 \mathrm{~nm})$ of the SOF estimated by semiempirical calculations at the PM3 level.

Fluorescence spectroscopy was then used to investigate the photophysical properties of $\mathbf{1}$ and the as-formed 2D SOF. As shown in Fig. 3, the fluorescence emission spectrum of an aqueous solution of 1 indicated that it was almost fluorescence silent. However, a strong emission peak centered at around $575 \mathrm{~nm}$ was observed for an aqueous solution of the 2D SOF. Compared to compound 1, a 35 -fold increase of fluorescence intensity was observed after it was co-assembled with $\mathrm{CB}[8]$ to form the $2 \mathrm{D}$ SOF. This phenomenon might be explained by two possible processes. Firstly, the non-emission of $\mathbf{1}$ might be attributed to an intramolecular charge transfer between the electron-rich 


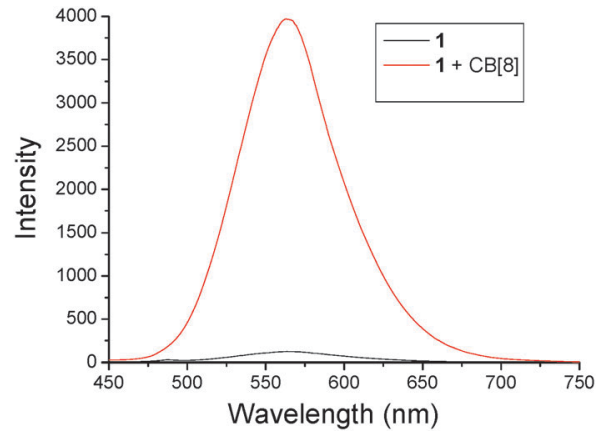

Fig. 3 Fluorescence spectra of $1\left(2.0 \times 10^{-7} \mathrm{M}\right)$ without and with $\mathrm{CB}[8]$ $\left(3.0 \times 10^{-7} \mathrm{M}\right)$ in water. $\lambda_{\mathrm{ex}}=414 \mathrm{~nm}$.

triphenylamine segment and the electron-deficient pyridinium unit. Upon the formation of the 2D SOF, the charge-transfer was blocked by the encapsulation of the pyridinium unit in the cavity of $\mathrm{CB}[8]$. As a result, fluorescence emission restored. Secondly, the observed enhanced emission might be explained by aggregation-induced emission (AIE) theory. ${ }^{10}$ According to the theory, compound $\mathbf{1}$ was fluorescence silent in solution because of the free rotation of the molecular skeleton, which leads to thermal relaxation of the $S_{1}$ state of excited 1 . The co-assembly of 1 with $\mathrm{CB}[8]$ led to the formation of the $2 \mathrm{D}$ SOF, in which the building blocks were confined in $2 \mathrm{D}$ spaces to generate a rigid $2 \mathrm{D}$ network. It inhibited the free rotation and thus dictated energy relaxation of $S_{1}$ to $S_{0}$ through radiation. In order to investigate which route is more reasonable, a control experiment was carried out. In the control experiment, $\mathrm{CB}[7]$, a homolog of $\mathrm{CB}[8]$ but has a smaller cavity and can only encapsulate one MPP unit in its cavity, was used to titrate compound 1 in water. The titration was monitored by fluorescence spectroscopy and it revealed that the intensity of the solution of 1 displayed almost no change upon the addition of $\mathrm{CB}[7]$ (Fig. S6, ESI $\dagger$ ). This result clearly indicates that the first assumption is not reasonable and the emission enhancement should be attributed to the AIE effect, as a result of the formation of the rigid 2D SOF.

Since triphenylamine is an electron-rich segment, we further exploited the as-formed 2D SOF as a fluorescent chemosensor to detect nitroaromatic explosives which are electron-deficient. 13 nitroaromatics whose structures are shown in Fig. 4 were chosen for this purpose. Photoluminescence spectra of the 2D SOF in the presence of the selected nitroaromatics were recorded (Fig. S7, ESI $\dagger$ ). As can be seen in Fig. 4a, the 2D SOF exhibited excellent selectivity toward picric acid. Upon the addition of the same amount of nitroaromatics $\left(1.6 \times 10^{-4} \mathrm{M}\right)$, PA led to $c a$. $90 \%$ quenching of the emission of the $2 \mathrm{D} \mathrm{SOF}$, while other nitroaromatics showed little influence on the emission of the SOF, except that nitroaniline (3) led to $c a$. 55\% quenching (Fig. 4a). The significant fluorescence emission quenching by PA could be attributed to the charge transfer between it and triphenylamine cores of the 2D SOF. It should be noted that the electron density of triphenylamine cores in the 2D SOF considerably decreased by the attachment of the pyridinium units. As a result, it only interacts with highly electron-deficient species such as PA.
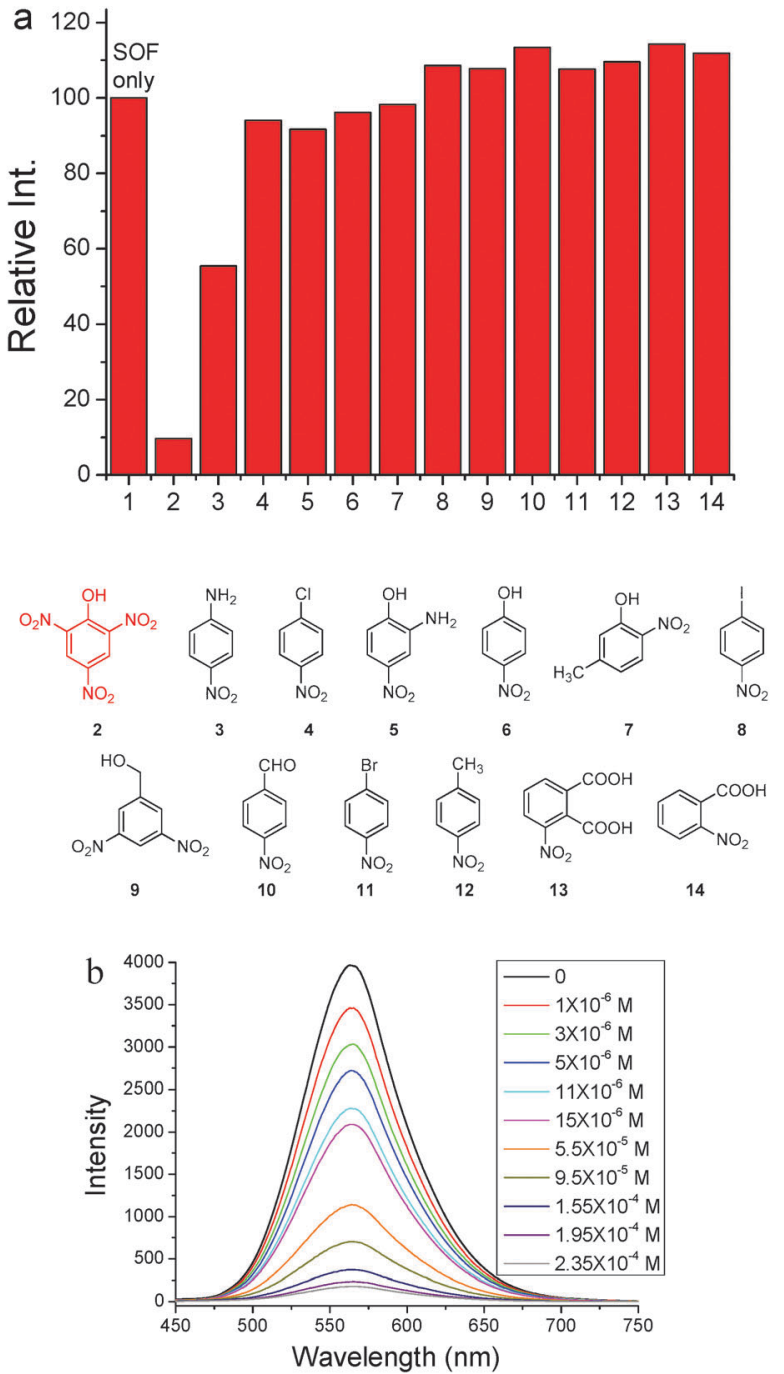

Fig. 4 (a) Changes in the fluorescence intensity of the 2D SOF upon the addition of different nitroaromatics, and (b) fluorescence spectra of the 2D SOF in the presence of different amounts of PA in water. The concentration of 1 in the SOF was $2.0 \times 10^{-7} \mathrm{M}$.

For the other nitroaromatic compounds, their electron deficiencies are not as strong as PA, as they bear less nitro groups. Therefore, charge transfer between them and triphenylamine cores is quite weak, which results in no significant change in the emission of the $2 \mathrm{D}$ SOF.

Fluorescence titration of the 2D SOF with PA was further conducted, which indicated a decrease of emission intensity of the 2D SOF as the PA concentration increased (Fig. 4b). A significant $13 \%$ luminescence quenching was observed even in the presence of only $1 \mathrm{ppm}$ PA. The emission was almost completely quenched when the concentration of PA reached $2.35 \times 10^{-4} \mathrm{M}$. The limit of PA detection was estimated to be $0.82 \mathrm{ppm}$ (Fig. S8, ESI $\dagger$ ). Such high sensitivity could be attributed to the $2 \mathrm{D}$ feature of the SOF which provides a huge surface to interact with PA molecules in the solution.

In summary, by taking advantage of the excellent host-guest interaction between $\mathrm{CB}[8]$ and MPP units, a single-layer 2D SOF 
has been constructed in aqueous solution through the co-assembly of $\mathrm{CB}[8]$ and a triphenylamine-based rigid $\mathrm{C}_{3}$ symmetric building block which provided excellent direction control of the formation of the 2D network. A ca. 35-fold fluorescence emission enhancement was observed upon the formation of the soluble 2D SOF. The as-prepared 2D SOF was further found to be an excellent fluorescent chemosensor to detect picric acid with high selectivity and sensitivity. The interesting properties and application of this 2D SOF demonstrate that emerging 2D supramolecular architectures can be useful platforms to fabricate functional soft materials. In this context, more applications can be expected from 2D SOFs as their unique structures can create versatile interesting properties.

We thank the National Natural Science Foundation of China (No. 21472225 and 21402228) and the Technology Commission of Shanghai Municipality (15ZR1449500) for the financial support and the Shanghai Synchrotron Radiation Facility for collecting the synchrotron X-ray scattering data.

\section{Notes and references}

1 M. O'Keeffe and O. M. Yaghi, Chem. Rev., 2012, 112, 675.

2 P. J. Waller, F. Gándara and O. M. Yaghi, Acc. Chem. Res., 2015, 48, 3053 .

3 (a) S.-Y. Ding and W. Wang, Chem. Soc. Rev., 2013, 42, 548; (b) J.-R. Li, J. Sculley and H.-C. Zhou, Chem. Rev., 2012, 112, 869; (c) Z.-Y. Gu, J. Park, A. Raiff, Z. Wei and H.-C. Zhou, ChemCatChem, 2014, 6, 67; (d) S.-Y. Ding, M. Dong, Y.-W. Wang, Y.-T. Chen, H.-Z. Wang, C.-Y. Su and W. Wang, J. Am. Chem. Soc., 2016, 138, 3031; (e) G. Das, B. P. Biswal, S. Kandambeth, V. Venkatesh, G. Kaur, M. Addicoat, T. Heine, S. Verma and R. Banerjee, Chem. Sci., 2015, 6, 3931; $(f)$ D. Liu, K. Lu, C. Poon and W. Lin, Inorg. Chem., 2014, 53, 1916.

4 (a) T. Xiao, X. Feng, Q. Wang, C. Lin, L. Wang and Y. Pan, Chem. Commun., 2013, 49, 8329; (b) X. Yan, D. Xu, X. Chi, J. Chen, S. Dong, X. Ding, Y. Yu and F. Huang, Adv. Mater., 2012, 24, 362; (c) D.-S. Guo and Y. Liu, Chem. Soc. Rev., 2012, 41, 5907; (d) A. Aydogan and J. L. Sessler, Chem. Commun., 2014, 50, 13600; (e) D.-H. Qiu, Q.-C. Wang, Q.-W. Zhang, X. Ma and H. Tian, Chem. Rev., 2015, 115, 7543; (f) Y. Han, Z. Meng, Y.-X. Ma and C.-F. Chen, Acc. Chem. Res., 2014, 47, 2026; $(g)$ M. Xue, Y. Yang, X. Chi, Z. Zhang and F. Huang, Acc. Chem. Res., 2012, 45, 1294.

5 (a) K. I. Assaf and W. M. Nau, Chem. Soc. Rev., 2015, 44, 394; (b) X.-L. Ni, X. Xiao, H. Cong, Q.-J. Zhu, S.-F. Xue and Z. Tao, Acc. Chem. Res., 2014, 47, 1386; (c) J. Lagona, P. Mukhopadhyay, S. Chakrabarti and L. Isaacs, Angew. Chem., Int. Ed., 2005, 44, 4844; (d) L. Isaacs, Chem. Commun., 2009, 619.

6 (a) Y. H. Ko, E. Kim, I. Hwang and K. Kim, Chem. Commun., 2007, 1305; (b) K. Kim, N. Selvapalam, Y. H. Ko, K. M. Park, D. Kim and J. Kim, Chem. Soc. Rev., 2007, 36, 267; (c) Y. Liu, H. Yang, Z. Wang and X. Zhang, Chem. - Asian J., 2013, 8, 1626; (d) Z. Huang, L. Yang, Y. Liu, Z. Wang, O. A. Sherman and X. Zhang, Angew. Chem., Int. Ed., 2014, 53, 5351; (e) Y. Liu, Z. Huang, X. Tan, Z. Wang and X. Zhang, Chem. Commun., 2013, 49, 5766; $(f)$ J. d. Barrio, P. N. Horton, D. Lairez, G. O. Lloyd, C. Toprakcioglu and O. A. Sherman, J. Am. Chem. Soc., 2013, 135, 11760; (g) Z.-J. Zhang, H.-Y. Zhang, L. Chen and Y. Liu, J. Org. Chem., 2011, 76, 8270; (h) T.-T. Cao, X.-Y. Yao, J. Zhang, Q.-C. Wang and X. Ma, Chin. Chem. Lett., 2015, 26, 867.

7 (a) K.-D. Zhang, J. Tian, D. Hanifi, Y. Zhang, A. Chi-H. Sue, T.-Y. Zhou, L. Zhang, X. Zhao, Y. Liu and Z.-T. Li, J. Am. Chem. Soc., 2013, 135, 17913; (b) L. Zhang, T.-Y. Zhou, J. Tian, H. Wang, D.-W. Zhang, X. Zhao, Y. Liu and Z.-T. Li, Polym. Chem., 2014, 5, 4715; (c) S.-Q. Xu, X. Zhang, C.-B. Nie, Z.-F. pang, X.-N. Xu and X. Zhao, Chem. Commun., 2015, 51, 16417; (d) T.-Y. Zhou, Q.-Y. Qi, Q.-L. Zhao, J. Fu, Y. Liu, Z. Ma and X. Zhao, Polym. Chem., 2015, 6, 3018; (e) M. Pfeffermann, R. Dong, R. Graf, W. Zajaczkowshi, T. Gorelik, W. Pisula, A. Narita, K. Müllen and X. Feng, J. Am. Chem. Soc., 2015, 137, 14525; $(f)$ J. Tian, L. Chen, D.-W. Zhang, Y. Liu and Z.-T. Li, Chem. Commun., 2016, 52, 6351.

8 (a) J. Tian, T.-Y. Zhou, S.-C. Zhang, S. Aloni, M. Virginia, S.-H. Xie, H. Wang, D.-W. Zhang, X. Zhao, Y. Liu and Z.-T. Li, Nat. Commun., 2014, 5, 5574; (b) L. Zhang, Y. Jia, H. Wang, D.-W. Zhang, Q. Zhang, Y. Liu and Z.-T. Li, Polym. Chem., 2016, 7, 1861; (c) J. Tian, Z.-Y. Xu, D.-W. Zhang, H. Wang, S.-H. Xie, D.-W. Xu, Y.-H. Ren, Y. Wang, Y. Liu and Z.-T. Li, Nat. Commun., 2016, 7, 11580; (d) X.-M. Chen, Y.-M. Zhang and Y. Liu, Supramol. Chem., 2016, DOI: 10.1080/ 10610278.2016.1158406.

9 (a) Y. Zhang, T.-Y. Zhou, K.-D. Zhang, J.-L. Dai, Y.-Y. Zhu and X. Zhao, Chem. - Asian J., 2014, 9, 1530; (b) T.-Y. Zhou, Q.-Y. Qi, Y. Zhang, X.-N. Xu and X. Zhao, Org. Chem. Front., 2015, 2, 1030.

10 (a) J. Luo, Z. Xie, J. W. Y. Lam, L. Cheng, H. Chen, C. Qiu, H. S. Kwok, X. Zhan, Y. Liu, D. Zhu and B. Z. Tang, Chem. Commun., 2001, 1740; (b) D. Ding, K. Li, B. Liu and B. Z. Tang, Acc. Chem. Res., 2013, 46, 2441. 